\title{
SUPPORTING ACADEMIC PUBLICATION: EVALUATION OF A WRITING COURSE COMBINED WITH WRITERS' SUPPORT GROUP
}

\begin{abstract}
Publication rates are a vital measure of individual and institutional performance, yet many nurse academics publish rarely or not at all. Despite widespread acceptance of the need to increase academic publication rates and the pressure university faculty may experience to fulfil this obligation, little is known about the effectiveness of practical strategies to support academic writing. In this small cohort study $(\mathrm{n}=8)$ comprising nurses and other professionals involved in university education, a questionnaire survey was used to evaluate the effectiveness of a one-week "Writing for Publication" course combined with a monthly writers support group to increase publication rates. Two-year pre and post submissions increased from 9 to 33 articles in peer-reviewed journals. Publications (in print) per person increased from a baseline of 0.5 to 1.2 per year. Participants reported increased writing confidence and greater satisfaction with the publishing process. Peer support and receiving recognition and encouragement from line managers were also cited as incentives to publish. Writing for publication is a skill that can be learned. The evaluated model of a formal writing course, followed by informal monthly group support meetings, can effectively increase publication rates.

(186 words)
\end{abstract}

\section{$\underline{\text { Keywords }}$}

Academic; Writing for publication; Writing course; Writing support group; Questionnaire. 


\section{INTRODUCTION}

Academic publication rates are used internationally as an indicator of both individual and institutional performance, and there are promotional and financial imperatives to publish (Creamer 1998; Emden 1998; Ramsden 1994). In Australia, publication rates influence the level of funding provided by government and other granting bodies (Australian Government National Health and Medical Research Council 2007; Australian Government Department of Education, Science and Training 2005; Creamer 1998; Emden 1998; Ramsden 1994). Financial incentives are linked to publication rates in many countries ranging from the UK to Mexico (Bence \& Oppenheim 2004; Teodorescu 2000). However, despite widespread acknowledgement of the need to publish, overall academic publication outputs remain low, especially among nurses (Keen 2007).

\section{BACKGROUND}

In Australia average academic publication rates less than 0.5, 0.6 and 1.0 per year have been reported (Emden 1998; Ramsden 1994; Harris 1990; West et al. 1980). Although a minority of academics publish heavily, 20\%-25\% publish nothing in any given five-year period (Harris 1990; Ramsden 1994). Trends in other Western countries are similar. Data from 8,544 academics in the USA found that 41\% published nothing during 1998-1999, although this rate was halved in "research universities” (Sax et al. 2002). Another USA study found publications for 1990-2000 from 61 schools or departments found some achieved as little as three publications in a decade, with twelve institutions contributing $44 \%$ literature published in this period (Green et al. 2002).

Publication has been reported to be inhibited by many factors. Lack of time is frequently cited (Page-Adams et al. 1995) yet highly productive writers have not been shown to have more 
time or fewer commitments than their non-writing colleagues (Boice \& Jones 1984). Fear and anxiety have also been cited as significant factors for a number of academics (Dies 1993; Lee \& Boud 2003). Female gender has traditionally been linked to lower publication outputs, although the gap is narrowing (Sax et al. 2002). Factors linked to publication success include younger age, higher rank, higher institutional and departmental prestige, intrinsic motivation to conduct research and be recognised, high autonomy and low job stress (Sax et al. 2002).

A recent review by McGrail et al. (2006) critiqued reported interventions designed to increase publication rates. In 17 publications, three intervention models were found to have been tested in various settings; fifteen of these were in North America. These models were a writing course, a writing support group, and a writing coach. All were found to be effective ways to increase publication rates. Other benefits reported included an increase in confidence, skills and teamwork. There was some indication that writing support groups generated better improvements in publication rates than writing courses or coaches, and that longer courses were more effective than shorter ones (McGrail et al. 2006). The publications had limitations such as small sample size, lack of a control group, and likely publication bias. However, the consistency of positive effect suggests that a formal intervention of any one of these models is likely to result in improved publication rates for participants.

Although the literature review described above suggests that a writing course, writing support group, or writing coach increases publication rates, it is not known which aspects of these programs are most facilitative. One strategy not previously assessed is a combined intervention. Encouraging academics to publish involves behavioural change, an area where a multifaceted, rather than single-intervention approach may be more useful. 


\section{$\underline{\text { Aim }}$}

The aim of this project was to explore the experiential aspects and the effectiveness of a combined approach — structured writing course plus writing support group—on academic publication rates.

\section{METHOD}

The Monash University School of Rural Health in Victoria, Australia, provides tertiary education in a range of health disciplines, including nursing. This was an evaluation study of the effectiveness of the Monash University combined writing course and writing support group on academic publication rates in the following two year period.

\section{The Writing Course}

An intensive, external-consultant-led “Writing for Publication” course was held over five days in February 2002 (Brown 2006). Participants were required to have a project they could write about, with the stages of data analysis and literature review completed prior to the course. Preparatory material including a draft manuscript was developed in the weeks prior to the course, and most participants had lead up contact with the consultant via email and or phone calls. The course consisted of formal sessions on how to write for publication, group discussions of each others' writing, dedicated writing time, and individual guidance and/or editing from the consultant. The course provided a step-by-step analysis of writing articles, focussing on abstracts and introductions, methods, results and discussion. Part of each day was devoted to writing time, with the consultant available for feedback on common style problems, analysing published papers, and strategies for answering reviewers’ criticisms (Brown 2006). On the final day, the authors prepared and exchanged detailed critiques of each manuscript. 


\section{The Writing Support Group}

Eight participants (including six authors of this paper) from a variety of academic disciplines, including nursing, science, social science, and humanities, attended four-hour writing support meetings once a month. The day of meeting had no formal structure and no dedicated leader. Participants were encouraged or supported by their peers to continue writing, present drafts for review and discuss new research and writing ideas. "Reporting back" was also held at each session, with achievement of submission, acceptance and publication duly celebrated, and support/advice given when manuscripts were rejected or criticised by editors. Five persons attended more than ten group meetings in the subsequent two years; two people attended five to ten meetings, and one person less than five.

\section{$\underline{\text { Participants }}$}

The majority of participants were at Level A (Research Assistant/Associate Lecturer) or B (Research Fellow/Lecturer), with one attendee each from level C (Senior Lecturer) and D (Associate Professor). There were six female and two male attendees, with ages ranging from 25-55 years. Participants had varying experience in academic employment (from less than one to many years) and were from a range of disciplines, as described above. About half were qualified or enrolled at the Masters or PhD level. Specific demographic data was not recorded to maintain anonymity.

\section{Study Procedure}

Two years after the writing course, writing group participants were invited to complete an anonymous web-based questionnaire to report on their experiences in the project and their resultant publication history. Questions were developed by three of the authors (CR, MM, RJ) 
using concepts identified in the literature and from previous research (McGrail et al. 2006). To maintain anonymity, internet provider addresses and demographic data were not collected, and participants were aware of this. Completing the questionnaire was considered consent for the project. Participants were asked what they found to be the most and least beneficial aspects of the writing course and support group. They were also asked about articles published before and after attending the group meetings; number of group meetings attended; factors influencing attendance; and factors influencing publication. Anonymity was deemed important in capturing the experience of all participants. We particularly wanted to avoid participants feeling pressured to respond positively by overstating their publication rates, or conversely identify anyone as a "failure" for not publishing.

\section{$\underline{\text { RESULTS }}$}

In the two years prior to the course, the majority of participants had no publications. Two participants reported previous first-authored publication, but had published only one and two of these respectively. Two years after starting the group, seven participants had published at least one peer-reviewed article. Two-year pre and post submissions increased from nine to thirty-three articles in peer-reviewed journals. Those who attended more than ten support meetings submitted an average 5.4 manuscripts in the two year follow up period, compared with an average of 1.2 papers for those who attended less than ten meetings. Overall, publications (in print) per person increased from a baseline of 0.5 to 1.2 per year.

The participants reported that the main reason they attended the writing course was to improve their skills in writing and publishing. The perceived pressure to publish refereed articles was another common reason for attendance. The main reasons cited for attending the support meetings were intrinsic motivation to write, peer support, and a manageable 
workload. Workload was also the predominant reason given for non-attendance as well. After the course, five participants reported attending more than ten group meetings in the subsequent two years; two people attended between five and ten meetings, and one person less than five.

Common impediments to publishing cited by the participants included lack of time/competing workloads, insufficient opportunity to undertake research, environmental factors (shared/noisy offices), employment instability, unmotivated colleagues, and life demands. These factors are supported in the literature (Murray 2008; Keen 2007).

\section{Most and Least Beneficial Aspects of the Writing Course}

Participants nominated 23 strengths of the writing course and six least beneficial aspects out of which we derived meaning units (Tables 1 and 2). The best aspect for most attendees was the knowledge gained in the "how to" of writing a journal article. This was closely followed by the team experience of undertaking the course as a group. The only negative comment voiced by more than one attendee was that the time allowed for actual writing was not needed or was too long. This was in contrast to three others who noted this as a strength of the program.

\section{Most and Least Beneficial Aspects of the Support Group}

There were 26 nominated strengths of the support group and thirteen least beneficial aspects out of which we derived meaning units (Tables 3 and 4). The team atmosphere was seen as the most beneficial aspect, with attendees enjoying the peer support and intellectual feedback. All participants commented favourably on the fellowship and interaction with other group members. The majority also felt the regular meeting format and the feedback on their writing 
was valuable. Several respondents commented that the least beneficial aspect of the support group included the difficulty arranging meetings to suit all participants, resulting in small numbers. A quorum seems necessary; several participants commented on the loss of productivity at meetings with low attendance. However, the group nature of meetings was seen as an impediment to writing when noise or off-topic discussion created a distraction for some members.

In additional survey comments, the prominent factors seen as having promoted publication were increased writing confidence, feeling pressure to publish, having time to write, finding pleasure in writing and satisfaction in publishing, and receiving recognition and encouragement from line managers and peers.

\section{DISCUSSION}

Our results suggest that a one-week consultant-led writing course, followed by monthly peersupport writing meetings, is an effective strategy to increase academic publishing rates. Average publications per person per year increased from 0.5 to 1.2, a figure consistent with the average 1.1 publications per person per year post intervention found in 17 prior studies (McGrail et al. 2006). Perhaps more importantly, first-authorship on a published paper increased from two attendees prior to the course to seven in the follow up period. While the “minimum” or "ideal” academic publication rate per year is a contentious and complex issue, it seems reasonable to expect academics to publish at least once annually, and our data suggest that a writing course combined with support group can assist staff to achieve this.

Effectiveness of the writing course in the short term can be assessed by publication of coursemanuscripts. Of our respondents, six had published that particular article, and seven had 
published at least one article. Manuscripts were not all submission-ready at the end of the course (although most were close) and it is possible that without the regular writing group meetings they would not have been completed.

In the longer term, it appeared that the course/writing group combination had a sustained effect on increased publication rates, with almost all participants preparing multiple manuscripts during the next two years. It is possible that the increased publication activity of this group may not be sustained beyond this time and future research would be needed to ascertain the longer term effect. It is worth noting that respondents had an average 1.8 manuscripts submitted but not yet published at the two year mark, suggesting that publication rates in the third year post course would be equivalent or better than the first two years. Considering that most participants were junior academics with many working years ahead, the skills learnt and behavioural change achieved should stand them and their employers in good stead for some time. By the two year follow up, more than half of the original course participants had gone on to higher level academic positions or had commenced $\mathrm{PhD}$ studies. Although direct effects are unlikely, it is possible that the improved "track record" attained from the writing course and group contributed in boosting confidence.

Our study suggests that the type of academics attracted or suited to a writing course and support group may be those with: few previous publications, little confidence about writing for publication, a desire to improve writing skills and publication rates, and a feeling of external pressure to publish. It may be that a cohort assembled through stronger compulsion rather than our relative volunteerism may not have the same positive results that we observed. Two respondents whose supervisor "told them" to attend the writing course wrote the fewest number of articles over the follow up period. 
This writing course included large blocks of time for practical writing sessions; a feature noted as both most beneficial and least beneficial by different respondents. Inclusion in the course mandated that attendees had a specific article to write and much of the course involved writing, reading each others' work and giving feedback, redrafting, etc. A minority of attendees did not have a suitable project in progress, and this reinforces our recommendation that attendees at similar courses need to have a "ready to write" article in mind; that is, data needs to be analysed and literature reviewed prior to the course. Surprisingly, some academics had times with nothing to write about, and even expressed concern that they had "run out" of topics after the first paper/s were written. The course supervisor or writing group itself may need to assist staff to identify publishable topics and types of article. A lack of "data” does not preclude other types of writing such as editorials, literature and book reviews, case studies, or personal reflections (Driscoll \& Driscoll 2002).

At an individual level, writing for publication has two discrete aspects: specific knowledge related to writing and submitting material, and psychological factors such as writing confidence and fear. We found that the writing course followed by group support meetings addressed both these factors. Participants highly valued the formal instruction in how to prepare and structure an article, and how to submit and correspond with journals. Interaction with the course instructor was also important, with technical advice and positive feedback noted as highlights. Almost as important, however, was the group format of the course, which suggests that merely providing the material (e.g., as an on-line package or stand-alone lecture) would not be as well received. Group dynamics and interaction may be as important as the material presented, and may be a facilitative or an impeding influence. 
Certain characteristics of this support group led to the creation of norms around successful publishing and identification with the group. These characteristics included shared goals, voluntary attendance, no assigned leader, and lack of formal meeting structure. Team atmosphere, peer support and intellectual feedback were all highly rated by participants. Regular meetings provided deadlines and motivation, noted as useful by Cumbie et al. (2005). Once the team was established, in some ways it promoted its own sustainability; all except one participant said that continuing group support was a key reason for their attendance. The value placed on group interaction was not limited to the context of producing publications; participants described their experiences in terms such as "friendly" and "bonded together", which hints at relationships more akin to friendship than collegiality. It seems that workplace dynamics as well as publication rates may be improved by a writing group.

Having multiple researchers with a variety of perspectives also proved a strength, as noted by participants. Multidisciplinary colleagues can provide assistance with writing critique, even if they lack expertise about article content. In fact, the experience of explaining ideas to a group while intentionally avoiding discipline-specific jargon facilitated participants to improve their own clarity of meaning. In addition, the heterogeneity of disciplinary backgrounds proved beneficial in providing feedback on each others’ writing because the potential for topics being appropriated by others never arose, as it could have done in a discipline-specific group.

The major criticism of the group was the difficulty in organizing meetings to suit all members and the frustration of low attendance. A few members commented that the practical writing sessions were of minor benefit, as they found it distracting to work in a room with others. As discussed by McGrail et al. (2006), previous reports of writing groups have shown them to have one of two foci, either being a forum for writing and for receiving feedback on written 
work, or focusing on encouragement and discussion. This writing group included both aspects, but had no clear time delineation for either. Some participants clearly preferred one or the other approach and it may have been helpful to encourage people to attend part rather than the whole session.

Our writers’ group and those reported previously (McGrail et al. 2006) relied on voluntary attendance and participation. It is therefore important to understand factors that promote or detract attendance. We observed, as have others, that motivation levels of the members are crucial for success (Sommers et al. 1996). How motivation can be promoted is more difficult to assess. Clearly internal and external factors play a role. Some respondents found that institutional pressure to publish and a supervisor who supported their attendance were motivating. Other important factors included increased confidence in writing, having time to write, finding pleasure in writing, satisfaction of publishing, and recognition from peers. Workload was by far the most important barrier to attendance, even by respondents with the highest resultant publication rates. Group members were responsible for organising their own attendance in between teaching, research and other responsibilities, and they did not receive any dedicated time or reduction in workload to attend. This has been the case in previous research (Murray \& Newton 2008; Morss \& Murray 2001). Despite this, all participants attended at least some support group meetings. The geographical distance between participants from our multi-site school doubtless reduced attendance. In another study, distance was overcome by use of teleconference and website format (Cumbie et al. 2005). Making the support group an accepted part of departmental routine could take some of the organisational pressure off participants, allowing them to focus on their writing. 
Our study supports a combined course and writing group intervention to increase academic publication rates. However, there are several limitations inherent in the study design that engender caution in the interpretation of results. Firstly, it is possible that participants exaggerated their publication rates. We clearly asked for data only on published and submitted refereed journal articles, but it is possible that, for instance, respondents counted other writing such as refereed conference papers, or that they included papers in draft but not submitted and so on. Secondly, cumulative co-authored article numbers should be considered as inflated by as much as a factor of two, since many respondents were co-authors on each others’ papers. Although not mentioned by participants as a strength, we observed a greater increase in collaborative research and writing by group members during the course. Thirdly, this study was done in one school in the Australian setting, therefore responses may not be indicative of academics in other departments or countries. However, the study participants were from a range of multidisciplinary backgrounds, which suggests that it is the process that is important and not the disciplinary background of the participants. Strengths of our study were a reasonable follow up time and the provision of a clear breakdown of the type and number of manuscripts developed. We acknowledge, as have others, that there are shortcomings in the use of publication rates as an indicator of research or publication activity. One excellent paper in a top-ranking journal might be worth several in lesser forums, whilst some disciplines place higher regard on book authorship, others on journal articles (Sax et al. 2002). Nevertheless, publication rates are indisputably a frequent measure of quality and activity, and this situation shows no sign of changing.

The results of this, and previous studies, are biased in that participants were largely selfselecting and therefore had a pre-existing desire and at least some commitment to publish. It is possible that the group studied had a particular combination of personal or professional 
characteristics and a favourable interpersonal 'mix' that meant the intervention worked for them, but would not for others. On a cautionary note, a second cohort of academics from the same university participated in the identical course at a later stage, but very few chose to participate in the support group, and anecdotally outcomes were not as favourable. To find true cause and effect evidence, academics would need to be randomly assigned to receive the intervention or not, and then measured for a range of potentially confounding effects such as age, career level, and qualifications.

The study design involved participant-authors in a regional campus. This has limitations for results namely that the voices of authors have dominated over those of non-author participants. We are acutely aware that of the eight persons who participated, six were authors. This definitely limits our perspective and our preconceptions dominate in analysing the content. Although we found group support to be beneficial in stimulating writing, our findings may have been biased by the collegiality and positive experience of this particular group. Other writers may be more productive working alone or in smaller groups. Two respondents mentioned that noise or off-topic discussion in group meetings created a distraction for them. Different working styles must therefore be taken into account. We are also aware that researchers sharing preconceptions and experience may lead to false consensus. The incidental nature of our sample is a further source of low transferability, and our setting may have had a effect on our results. This rural setting may not reflect all academic settings. A monthly group meeting might have extra connotations in a rural setting where opportunities for social and intellectual stimulation for academics may be reduced.

Our study is a reflective experience of motivated (due to various reasons) academics attending a monthly writing support group meeting. In our experience, group support facilitated writing. 
We found that feedback, collegiality, identification, group norms, and support are the aspects which mediate positive effects.

\section{CONCLUSION}

Academic publication rates are a vital measure of individual and institutional performance and there is strong pressure internationally to improve output. Institutional pressure to publish, expressed in dictums like "publish or perish", is not of itself helpful for many staff. Writing for publication is a skill that can be learned and the evaluated model of a formal writing course, followed by informal monthly meetings of a multidisciplinary group, is an effective way to increase academic publication rates. 


\section{REFERENCES}

Australian Government Department of Education, Science and Training, 2005. Research quality framework: Assessing the quality and impact of research in Australia. http://www.dest.gov.au/sectors/research_sector/publications_resources/profiles/rqf_adv _approach.htm. Accessed 12 May 2008.

Australian Government National Health and Medical Research Council, 2007. Funding progress and final reporting. http://www.nhmrc.gov.au/funding/funded/manage/policy/progreport.htm. Accessed 12 May 2008.

Bence V., Oppenheim C., 2004. The role of academic journal publications in the UK. Research Assessment Exercise. Learned Publishing, 17 (1), 53-68.

Boice, R., Jones, F., 1984. Why academicians don't write. Journal of Higher Education, 55 (5), 567-582.

Brown, R., 2006. WriteWay Consulting. Brisbane. robertbrown1@optusnet.com.au Creamer, E.G., 1998. Accessing faculty publication productivity: Issues of equity. ASHEERIC higher education report. 26 (2).

Cumbie, S., Weinert, C., Luparell, S., Conley, V., Smith, J., 2005. Developing a scholarship community. Journal of Nursing Scholarship, 37 (3), 289-293.

Dies, R.R., 1993. Writing for publication: Overcoming common obstacles. International Journal of Group Psychotherapy, 43 (2), 243-249.

Driscoll, J., Driscoll, A., 2002. Writing an article for publication: An open invitation. Journal of Orthopaedic Nursing, 6, 144-152.

Emden, C., 1998. Establishing a "track record": Research productivity and nursing academe. Australian Journal of Advanced Nursing, 16 (1), 29-33. 
Green, R.G., Baskind, F.R., Bellin, M.H., 2002. Results of the doctoral faculty publication project: journal article productivity and its correlates in the 1990s. Journal of Social Work Education, 38 (1), 135-152.

Harris, G.T., 1990. Research output in Australian economics departments: An update for 1984-1988. Australian Economic Papers, 29 (55), 249-259.

Keen, A., 2007. Writing for publication: Pressures, barriers and support strategies. Nurse Education Today, 27, 382-388.

Lee, A., Boud, D., 2003. Writing groups, change and academic identity: Research development as local practice. Studies in Higher Education, 28 (2), 187-200.

McGrail, M.R., Rickard, C.M., Jones, R., 2006. Publish or perish: A systematic review of interventions to increase academic publication rates. Higher Education Research and Development, 25 (1), 19-35.

Morss, K., Murray, R., 2001. Researching academic writing within a structured programme: Insights and outcomes. Studies in Higher Education, 26 (1), 35-42.

Murray, R., Newton, M., 2008. Facilitating writing for publication. Physiotherapy, 94, 29-34.

Page-Adams, D., Cheng, L.-C., Gogineni, A., Shen, C.-Y., 1995. Establishing a group to encourage writing for publication among doctoral students. Journal of Social Work Education, 31 (3), 402-407.

Ramsden, P., 1994. Describing and explaining research productivity. Higher Education, 28 (2), 207-226.

Sax, L.J., Hagedorn, L.S., Arredondo, M., Dicrisi, F.A., 2002. Faculty research productivity: Exploring the role of gender and family-related factors. Research in Higher Education, 43 (4), 423-445.

Sommers, P.S., Muller, J.H., Bailiff, P.J., Stephens, G.G., 1996. Writing for publication: A workshop to prepare faculty as medical writers. Family Medicine, 28 (9), 650-654. 
Teodorescu, D., 2000. Correlates of faculty publication productivity: A cross-national analysis. Higher Education, 39, 201-222.

West, L.H., Hore, T., Boon, P.K., 1980. Publication rates and productivity. Vestas, 23, 32-37.

(4440 words) 
Table 1. Most beneficial aspects of writing course

\begin{tabular}{|c|c|c|c|}
\hline Theme & $\mathbf{N}^{*}$ & Items & Excerpts \\
\hline $\begin{array}{r}\text { Learning the } \\
\text { writing process }\end{array}$ & 8 & $\begin{array}{r}\text { How to structure an article } \\
\text { How to write an abstract/title } \\
\text { How to synthesize an } \\
\text { argument }\end{array}$ & $\begin{array}{l}\text { "I really liked the framework } \\
\text { presented about how to structure an } \\
\text { "How to get to the hub of the issue" }\end{array}$ \\
\hline Group format & 6 & $\begin{array}{r}\text { Feeling of fellowship } \\
\text { Realising shared experiences } \\
\text { Developing interpersonal } \\
\text { relationships } \\
\text { Establishing a team for the } \\
\text { future workshops }\end{array}$ & $\begin{array}{l}\text { "Reassurance that it wasn't just me } \\
\text { that struggled" } \\
\text { "Sense of academic fellowship" } \\
\text { "Bonding and fun experience" } \\
\text { "It set the tone for the future writing } \\
\text { sessions" }\end{array}$ \\
\hline $\begin{array}{r}\text { Practical writing } \\
\text { sessions }\end{array}$ & 2 & Time to write & “The emphasis on 'hands on'” \\
\hline $\begin{array}{r}\text { Receiving } \\
\text { positive feedback }\end{array}$ & 2 & $\begin{array}{r}\text { From peers } \\
\text { From consultant }\end{array}$ & $\begin{array}{l}\text { "Positive feedback that I had the } \\
\text { ability to write" }\end{array}$ \\
\hline $\begin{array}{r}\text { Learning the } \\
\text { submission } \\
\text { process }\end{array}$ & 2 & $\begin{array}{r}\text { Standards required for } \\
\text { publishing } \\
\text { How to communicate with } \\
\text { journals }\end{array}$ & $\begin{array}{r}\text { "Understanding what editors expect" } \\
\text { "Responding to reviewers' } \\
\text { comments" }\end{array}$ \\
\hline $\begin{array}{r}\text { Week-long } \\
\text { format }\end{array}$ & 1 & Timeframe favourable & "Valuable that it was a week long" \\
\hline $\begin{array}{r}\text { Discussion } \\
\text { sessions }\end{array}$ & 1 & Intellectual stimulation & "Intellectual discussion with peers" \\
\hline Visibility & 1 & $\begin{array}{r}\text { Enhanced professional } \\
\text { reputation }\end{array}$ & $\begin{array}{r}\text { "Colleagues... more aware of my } \\
\text {...abilities" }\end{array}$ \\
\hline Total & 23 & & \\
\hline
\end{tabular}

- Citations 


\begin{tabular}{|c|c|c|c|}
\hline Theme & $\mathbf{N}^{*}$ & Items & Excerpts \\
\hline $\begin{array}{r}\text { Practical writing } \\
\text { sessions }\end{array}$ & 2 & $\begin{array}{r}\text { Time to write not useful } \\
\text { Practical writing blocks too } \\
\text { long }\end{array}$ & $\begin{array}{l}\text { "Large blocks of time for writing, } \\
\text {...waiting for further advice before } \\
\text { we could proceed" }\end{array}$ \\
\hline Course material & 1 & $\begin{array}{r}\text { Handouts sometimes } \\
\text { unavailable }\end{array}$ & $\begin{array}{r}\text { "Handouts were not always freely } \\
\text { available" }\end{array}$ \\
\hline $\begin{array}{r}\text { Learning the } \\
\text { writing process }\end{array}$ & 2 & $\begin{array}{r}\text { Basic grammar review } \\
\text { unnecessary } \\
\text { Scientific article structure not } \\
\text { always suitable }\end{array}$ & $\begin{array}{r}\text { "Basic English grammar tips...not } \\
\text { necessary" } \\
\text { “Assumption that all articles are } \\
\text { based on an 'experiment'... } \\
\text { however... this... was modified" }\end{array}$ \\
\hline Group format & 1 & $\begin{array}{r}\text { Other participants not } \\
\text { contributing }\end{array}$ & $\begin{array}{r}\text { "Frustrating that some attended with } \\
\text { no article" }\end{array}$ \\
\hline Nothing & 3 & - & $\begin{array}{r}\text { "I thought the whole course was } \\
\text { excellent" }\end{array}$ \\
\hline lotal & 6 & & \\
\hline
\end{tabular}

*Citations 
Table 3. Most beneficial aspects of writing support group

\begin{tabular}{|c|c|c|c|}
\hline Theme & $\mathbf{N}^{*}$ & Items & Excerpts \\
\hline Group Format & 8 & $\begin{array}{r}\text { Positive interpersonal } \\
\text { relationships } \\
\text { Peer support \& fellowship } \\
\text { Safe environment for honest } \\
\text { communication }\end{array}$ & $\begin{array}{r}\text { "The shared sense of achievement } \\
\text { amongst the group was an extremely } \\
\text { positive aspect" } \\
\text { "Supportive, friendly and non- } \\
\text { competitive" }\end{array}$ \\
\hline Motivation & 4 & $\begin{array}{l}\text { Feeling motivated to write } \\
\text { Receiving encouragement }\end{array}$ & $\begin{array}{r}\text { "Encouragement to continue writing } \\
\text { is my key benefit" }\end{array}$ \\
\hline $\begin{array}{r}\text { Monthly one-day } \\
\text { format }\end{array}$ & 4 & $\begin{array}{r}\text { Having a deadline to report } \\
\text { back to group } \\
\text { Dedicated time to write } \\
\text { without distraction }\end{array}$ & $\begin{array}{l}\text { "It encouraged me to write } \\
\text { something to present to the group" } \\
\text { “(not) distracted by email and } \\
\text { people" }\end{array}$ \\
\hline $\begin{array}{r}\text { Receiving } \\
\text { feedback }\end{array}$ & 5 & $\begin{array}{r}\text { Helpful feedback about } \\
\text { writing }\end{array}$ & $\begin{array}{r}\text { “Opportunity to ‘try’ your writing } \\
\text { on others” }\end{array}$ \\
\hline Giving feedback & 3 & Giving feedback to others & $\begin{array}{l}\text { “Assisted my own writing” } \\
\text { "Help other people” }\end{array}$ \\
\hline $\begin{array}{r}\text { Multidisciplinary } \\
\text { Approach }\end{array}$ & 2 & $\begin{array}{r}\text { Learning to write for various } \\
\text { readers } \\
\text { Value of input from different } \\
\text { perspectives }\end{array}$ & $\begin{array}{r}\text { "Feedback...from...people with a } \\
\text { range of experiences /backgrounds/ } \\
\text { perspectives/ strengths" }\end{array}$ \\
\hline Total & 26 & & \\
\hline
\end{tabular}

* Citations 
Table 4. Least beneficial aspects of writing support group

\begin{tabular}{|c|c|c|c|}
\hline Theme & $\mathbf{N}^{*}$ & Items & Excerpts \\
\hline $\begin{array}{r}\text { Organising } \\
\text { meetings }\end{array}$ & 4 & $\begin{array}{r}\text { Difficulty organising } \\
\text { meeting attendance } \\
\text { Poor attendance }\end{array}$ & $\begin{array}{l}\text { "Difficult to hold... when many } \\
\text { members have other commitments } \\
\text { and are unable to attend" }\end{array}$ \\
\hline Group format & 4 & $\begin{array}{r}\text { Low attendance decreases } \\
\text { effectiveness } \\
\text { Varying levels of } \\
\text { participation }\end{array}$ & $\begin{array}{l}\text { "If the group size gets too small } \\
(<4) \text {, (then the) format does not } \\
\text { work well" } \\
\text { "Less productive... as people drifted } \\
\text { off to meetings or (their office)" }\end{array}$ \\
\hline $\begin{array}{r}\text { Practical writing } \\
\text { time }\end{array}$ & 3 & $\begin{array}{r}\text { Not having a topic to write } \\
\text { about } \\
\text { Difficulty writing with others } \\
\text { in the room }\end{array}$ & $\begin{array}{r}\text { "When I didn't have writing to work } \\
\text { "I could not sit in the group and } \\
\text { write... distracting” }\end{array}$ \\
\hline Discussion time & 1 & $\begin{array}{r}\text { Discussion time reduced } \\
\text { writing time }\end{array}$ & "Too much talking and not writing" \\
\hline $\begin{array}{r}\text { Preparatory } \\
\text { reading }\end{array}$ & 1 & $\begin{array}{r}\text { Drafts circulated prior to } \\
\text { meeting not read }\end{array}$ & $\begin{array}{r}\text { "We could only commit time to read } \\
\text { on the day" }\end{array}$ \\
\hline Nothing & 2 & & "Nil” \\
\hline Total & 13 & & \\
\hline
\end{tabular}

* Citations 